\title{
Repeated recall and PKM $\zeta$ maintain fear memories in juvenile rats
}

\author{
Chicora F. Oliver, ${ }^{1}$ Patricia Kabitzke, ${ }^{2}$ Peter Serrano, ${ }^{3,4}$ Laura J. Egan, ${ }^{5}$ Gordon A. Barr, ${ }^{6}$ \\ Harry N. Shair, ${ }^{7}$ and Christoph Wiedenmayer ${ }^{7}$ \\ ${ }^{1}$ Department of Psychology, Brain and Cognitive Sciences, Temple University, Philadelphia, Pennsylvania 19122, USA; ${ }^{2}$ PsychoGenics, \\ Inc., Tarrytown, New York 10591, USA; ${ }^{3}$ The Graduate Center of CUNY, New York, New York 10016, USA; ${ }^{4}$ Department of \\ Psychology, Hunter College, New York, New York 10065, USA; ${ }^{5}$ Department of Psychology, Queens College, New York, New York \\ 11367, USA; ${ }^{6}$ Children's Hospital of Philadelphia and the Perelman School of Medicine, University of Pennsylvania, Philadelphia, \\ Pennsylvania 19104, USA; ${ }^{7}$ Division of Developmental Neuroscience, New York State Psychiatric Institute, New York, New York \\ 10032, USA
}

\begin{abstract}
We examined the neural substrates of fear memory formation and maintenance when repeated recall was used to prevent forgetting in young animals. In contrast to adult rats, juveniles failed to show contextual fear responses at $4 \mathrm{~d}$ post-fear conditioning. Reconsolidation sessions 3 and $6 \mathrm{~d}$ after conditioning restored contextual fear responses in juveniles $7 \mathrm{~d}$ after initial training. In juveniles that received reconsolidation sessions, protein kinase $\mathrm{M}$ zeta (PKM $\zeta$ ) increased in the amygdala, but not in the hippocampus. These data suggest that repeated reminders and increased PKM $\zeta$ maintain fear responses in juvenile animals that otherwise would not exhibit this behavior.
\end{abstract}

It is well established that young humans and animals rapidly forget, an observation that has been termed childhood or infantile amnesia (Campbell and Spear 1972). However, traumatic memories formed early in life can have a lasting impact on mental health (e.g., Heim and Nemeroff 2001). One way such memories persist is through repeated recall with periodic reminders, making a memory more persistent in children (Rovee-Collier et al. 1980; Hayne 1990) and young animals (Campbell and Jaynes 1966). The mechanisms of this phenomenon, called reconsolidation, remain largely unknown. Using an ecologically relevant stimulus to induce fear (Wiedenmayer and Barr 2001; Wiedenmayer et al. 2005), we examined the mechanisms of fear memory formation and maintenance during early development using predator odor exposure in rats to model traumatic events in young humans.

The amygdala and hippocampus play vital roles in fear memory formation (Phillips and LeDoux 1992) and maintenance (Amaral et al. 2007; Baldi et al. 2008). Protein kinase M zeta (PKM $\zeta)$ is a persistently active memory-related protein kinase (Sacktor 2008) associated with maintaining spatial long-term memory (LTM) in the hippocampus (Pastalkova et al. 2006; Sebastian et al. 2013) and contextual fear memories in the amygdala (Serrano et al. 2008; Kwapis et al. 2012). Overexpression of PKM $\zeta$ enhances contextual fear memories (Schuette et al. 2016). Thus, we examined PKM $\zeta$ during contextual fear memory formation and maintenance in the amygdala and hippocampus of young animals.

Due to the active development of structures involved in fear memory formation prior to adulthood (Spear 2000), we hypothesized that (1) juveniles will form fear memories but will not maintain them for as long as adults and (2) reconsolidation sessions will serve as periodic reminders of training and prevent forgetting in young animals. Despite known differences, e.g., the role of corticosterone (Upton and Sullivan 2010; Hostinar et al. 2014), many of the mechanisms of fear memory formation and maintenance in

Corresponding author: chicora.oliver@temple.edu

Article is online at http://www.learnmem.org/cgi/doi/10.1101/lm.042549. 116. the young may be similar to those in adults. Thus, we also hypothesized that (3) memories maintained by reconsolidation will coincide with an increase in $\mathrm{PKM} \zeta$ in the amygdala, but not in the hippocampus (Kwapis et al. 2012).

Male and female Long-Evans hooded rats were bred and reared at New York State Psychiatric Institute under standard conditions. Each group was balanced, as far as possible, by sex, age, and body weight. All procedures were approved by the Institutional Animal Care and Use Committee of New York State Psychiatric Institute according to NIH standards.

Contextual fear conditioning training, testing, and reconsolidation sessions took place in a clear rectangular cage $(42 \mathrm{~cm} \times 22$ $\mathrm{cm} \times 21 \mathrm{~cm}$ ), which was divided into two equally sized compartments with a wire mesh screen. One side of the cage was the stimulus side where an odor was placed, and the other side was identified as the rat compartment where home cage bedding was placed. Air was pumped at $5 \mathrm{~L} / \mathrm{min}$ (LPM) into the stimulus side of the cage with an air pump, and air was vacuumed out of the rat side of the cage at the same rate to facilitate odor removal during the intertrial intervals. The unconditioned stimulus (US) was $0.1 \mathrm{~mL}$ of rosemary oil applied to a paper towel, or a $4-\mathrm{cm}$ square cat pad that had been used by cats for several months and stored at $-80^{\circ} \mathrm{C}$. Cat odor is commonly used in fear learning as cats are natural rat predators (Mackenzie et al. 2010). In novel context control experiments, no home cage bedding was used and black and white striped paper was placed on the chamber walls. On training day (day 0), each rat was placed in the rat compartment of the testing chamber for a 5-min habituation period. A cat pad or control odor $(0.1 \mathrm{~mL}$ rosemary oil) was then placed in a dish behind the wire mesh screen for $5 \mathrm{~min}$, after which each rat was returned to its home cage.

\footnotetext{
C) 2016 Oliver et al. This article is distributed exclusively by Cold Spring Harbor Laboratory Press for the first 12 months after the full-issue publication date (see http://learnmem.cshlp.org/site/misc/terms.xhtml). After 12 months, it is available under a Creative Commons License (AttributionNonCommercial 4.0 International), as described at http://creativecommons. org/licenses/by-nc/4.0/.
} 


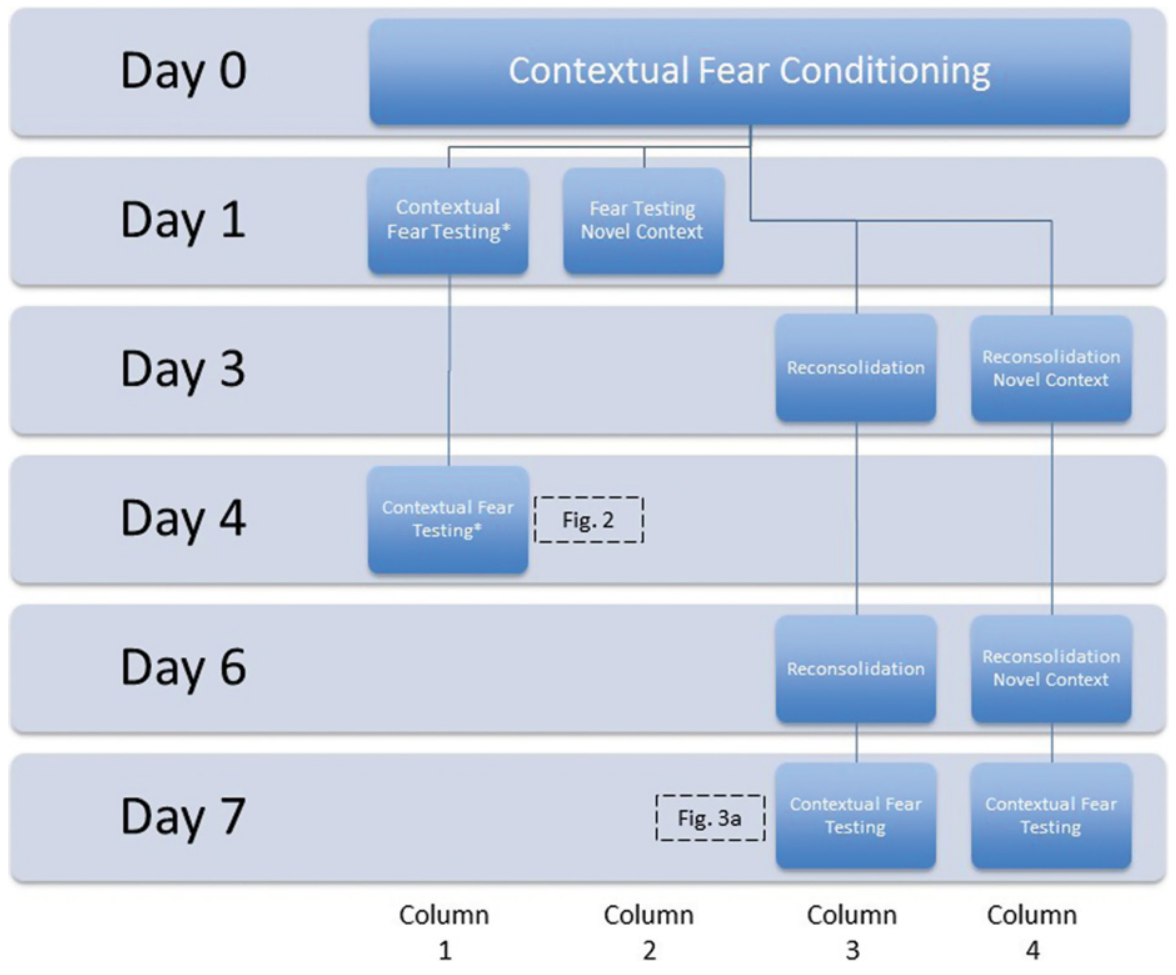

Figure 1. Schematic representation of experimental procedures. Asterisks indicate experiments that were conducted in adults as well as juveniles. Boxes with dashed outlines indicate the corresponding figures.

Juvenile (post-natal day 26) and adult rats (post-natal day 90) were tested for contextual fear responses 1 and $4 \mathrm{~d}$ after training (Fig. 1, Column 1; Fig. 2A,B). During testing, rats $(n=10-11$ per group) were placed in the rat compartment of the testing chamber for $5 \mathrm{~min}$ without the odor, and freezing was measured. Separate groups of juvenile and adult animals were tested for contextual fear 1 and $4 \mathrm{~d}$ after training in the initial experiment (Fig. 1, Column 1). When freezing at both testing, time intervals were compared in juveniles, there was a significant Stimulus $\times$ Session interaction $\left(F_{(1,20)}=9.4, P<0.01\right)$. One day after training, juveniles that had previously been exposed to cat odor exhibited significantly increased freezing compared with control odor-exposed rats (Newman-Keuls, $P<0.001$, Fig. $2 \mathrm{~A}$ ). In contrast, there was a significant effect of cat odor on freezing in adults $\left(F_{(1,20)}=\right.$ 21.6, $P<0.0001)$, but no interaction with day of testing. That is, adult animals exposed to cat odor froze at $1 \mathrm{~d}$ after training and continued to freeze to the context $4 \mathrm{~d}$ after training (Fig. 2B).

To determine whether freezing was specific to the context and did not reflect generalized anxiety, a separate set of juvenile rats ( $n=6$ per group) was placed in a novel context $1 \mathrm{~d}$ after contextual predator odor fear conditioning; freezing was recorded (Fig. 1, Column 2). These rats did not differ in freezing, showing that freezing was context-specific (control odor (mean \pm standard error) $3.5 \% \pm 2.5$, cat odor $3.0 \% \pm 1.9$, independent $t$-test, $P>$ $0.5)$.

A separate set of juveniles ( $n=10-11$ per group) that underwent contextual conditioning was given reconsolidation sessions 3 and $6 \mathrm{~d}$ after training (Fig. 1, Column 3). For reconsolidation sessions, rats were placed back in the training context without an odor three times for $5 \mathrm{~min}$ each, with 5-min intervals between context exposures and no observations made. Animals were returned to their home cage during the 5-min intervals between each 5-min context exposure. Brief, spaced exposures were used to reduce the possibility of extinction, which is known to occur with long, massed context exposures (Cain et al. 2003; Lee et al. 2006; Miguez et al. 2014). These animals were then tested 7 $\mathrm{d}$ after training ( $1 \mathrm{~d}$ after the second set of reconsolidation sessions). In the juveniles tested $7 \mathrm{~d}$ after initial training (Fig. 1, Column 3), a significant interaction (Stimulus $\times$ Reconsolidation interaction: $F_{(1,19)}=7.3, P<0.05$; Fig. $3 \mathrm{~A}$ ) revealed that cat odor-trained rats that received reconsolidation sessions froze significantly more than control rats or rats that did not receive reconsolidation sessions $(P<0.01)$.

To test the possibility that repeated exposure to the training context increased freezing, cat odor-exposed juvenile rats ( $n=5$ per group) were placed in a novel context $7 \mathrm{~d}$ after training (Fig. 1, Column 4). Half of these rats received reconsolidation sessions and the others did not. Freezing to the novel context was then compared between the groups. In the novel context, freezing did not differ between cat odor-exposed rats with or without repeated exposures to the original context $(2 \% \pm 2.7,1 \% \pm$ 2.2 , respectively; $t$-test, $P>0.5, n=5$ ).

Tissue from the hippocampus and amygdala of juvenile animals tested $7 \mathrm{~d}$
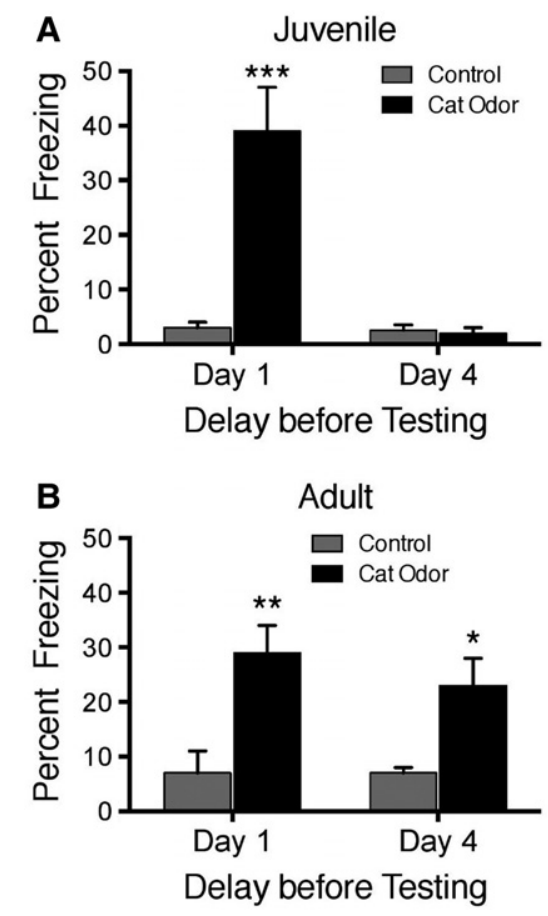

Figure 2. Adult and juvenile fear memory recall 1 and $4 \mathrm{~d}$ after contextual predator odor fear conditioning. $(A)$ Juvenile rats froze to the predator odor-trained context at 1 but not $4 \mathrm{~d}$ following training $(n=10-11$ per group). (B) Adult rats froze to the predator odor-trained context more than controls at 1 and $4 \mathrm{~d}$ following training ( $n=10-11$ per group) $\left(^{*}\right)$ $P<0.05 ;(* *) P<0.01 ;(* * *) P<0.001$. 
A
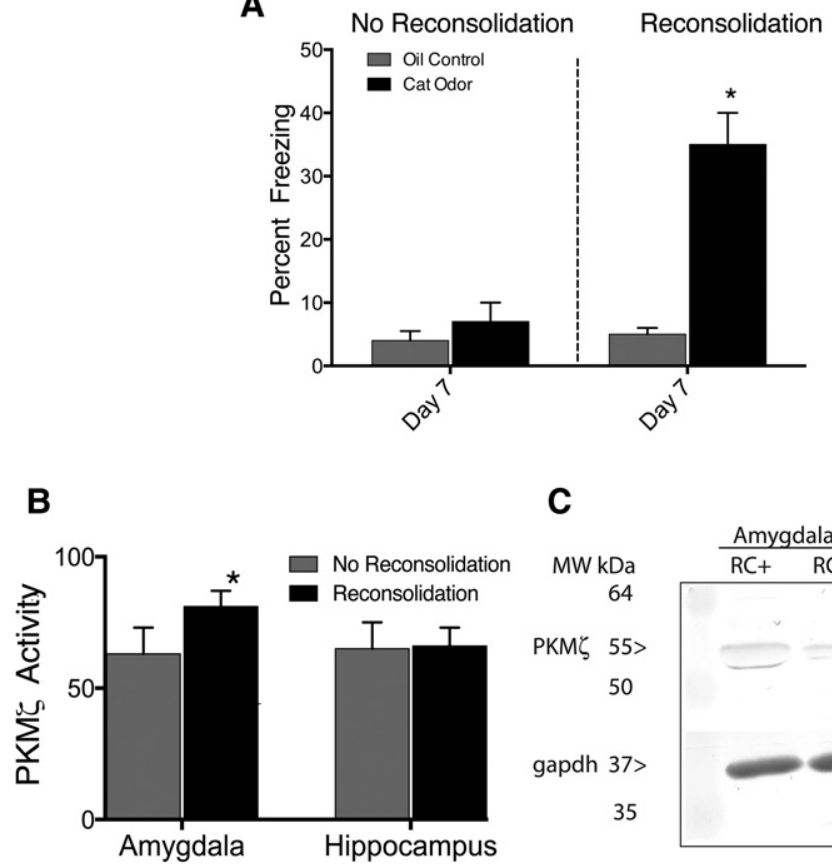

C

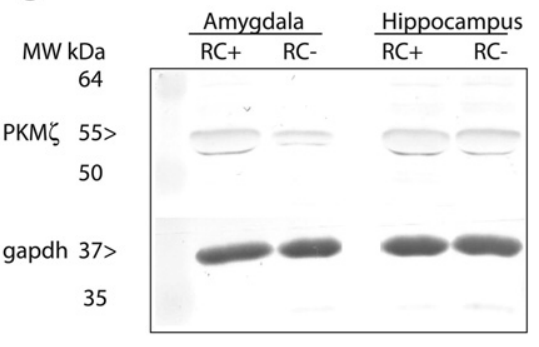

Figure 3. Reconsolidation behavior and PKM $\zeta$ activity in juvenile rats. $(A)$ Reconsolidation sessions extended predator odor contextual fear memory to $7 \mathrm{~d}$ following training ( $n=10$ per group). (B) PKM $\zeta$ (1:5000; Santa Cruz Biotechnology) protein expression increased in the amygdala but not hippocampus in juveniles given reconsolidation sessions ( $n=4-5$ per group). (C) Representative immunoblots of PKM $\zeta$ protein expression in the amygdala and hippocampus in juveniles given reconsolidation sessions $(\mathrm{RC}+)$ and juveniles not given reconsolidation sessions $(\mathrm{RC}-)\left({ }^{*}\right) P<0.05$.

after training, with and without reconsolidation sessions, were prepared into cytosolic fractions as previously reported (Sebastian et al. 2013). Each group consisted of four to five animals. Briefly, tissues were thawed and homogenized in $200 \mu \mathrm{L}$ of TEE (Tris 50 mM; EDTA 1 mM; EGTA $1 \mathrm{mM}$ ) buffer containing SigmaFast, protease inhibitor cocktail (Sigma-Aldrich) diluted to contain AEBSF (2 mM), phosphoamiden (1 M), bestatin (130 M), E-64 (14 M), leupeptin $(1 \mathrm{M})$, aprotinin $(0.2 \mathrm{M})$, and pepstatin $\mathrm{A}(10 \mathrm{M})$. Tissues were homogenized with a motorized pestle, and homogenates were centrifuged at $3000 \mathrm{~g}\left(5 \mathrm{~min}\right.$ at $\left.4^{\circ} \mathrm{C}\right)$. The resulting supernatant was centrifuged at $100,000 \mathrm{~g}$ for $30 \mathrm{~min}$. After ultracentrifugation, the supernatant contained the cytosolic fraction. To quantify protein concentrations, we used the Pierce Bicinchoninic Acid assay (BCA) (Thermo Scientific). Samples were reduced with a $4 \times$ Laemmli sample buffer equivalent to $25 \%$ of the total volume of the sample and then boiled and stored at $-80^{\circ} \mathrm{C}$. Samples $(25 \mu \mathrm{g})$ were loaded onto a $4 \%-20 \%$ gradient gel to resolve tubulin $(50 \mathrm{kDa})$ and PKM $\zeta(55 \mathrm{kDa})$. Gels were then transferred to nitrocellulose membranes and blocked in solution containing $4 \%$ bovine serum albumin (BSA) in Tris-buffered saline with Tween-20 (TBST; 0.1\% Tween-20 in TBS) for $1 \mathrm{~h}$ at room temperature. Samples were incubated with PKM $(1: 5000$; Santa Cruz Biotechnology) or tubulin (1:5000, EMD Millipore). Blots were rinsed and probed with an alkaline phosphatasecoupled secondary antibody and developed with BCIP/NBT substrate (KPL). Membranes were then scanned for quantification with NIH Image J.

Rats that had been re-exposed to the context (reconsolidation) had significantly higher PKM $\zeta$ levels in the amygdala compared with rats that had not been re-exposed $(t(7)=2.42, P<$ 0.05 ; Fig. 3B). There was no difference hippocampal PKM $\zeta$ expression $(t(7)=0.09 ; P>0.05)$.
Thus, juveniles increased freezing to a context that had been previously paired with cat odor $24 \mathrm{~h}$ after training (Chan et al. 2011; Kabitzke et al. 2014); however, unlike adults, they failed to maintain the fear memory $4 \mathrm{~d}$ after training. Two reconsolidation sessions extended the predator odor-context memory in juveniles to $7 \mathrm{~d}$, and rats that received those reminders exhibited increased $\mathrm{PKM} \zeta$ in the amygdala but not the hippocampus. The results of this study suggest that $\mathrm{PKM} \zeta$ activity in the amygdala may play an important role in fear memory formation and LTM maintenance early in development, as it does in adults.

It should be noted that the lack of a contextual fear response in animals that did not receive reconsolidation sessions does not mean that these animals forgot the fear memory. In fact, many studies have demonstrated effects of seemingly forgotten early memories on both human/animal behavior and physiology (recently reviewed in $\mathrm{Li}$ et al. 2014). For example, heightened pMAPK in the amygdala suggests early learning in rats that do not behaviorally display a memory (Kim et al. 2012). Moreover, relearning a "forgotten" memory is NMDA receptor-independent, while original learning is not ( $\mathrm{Li}$ and Richardson 2013; Chan et al. 2014). Finally, most of the current literature uses a shock as the unconditioned stimulus; however, it is unclear whether predator odor is maintained in the same way and by the same mechanisms.

We do not believe that juvenile rats that failed to show fear memory $4 \mathrm{~d}$ after training would have spontaneously displayed the memory after 2 or more weeks, as has been shown in studies involving young mice (Pattwell et al. 2011). This is because, in the mouse experiments, memories that underwent temporary suppression during development (PN 29-PN 33) were not recalled $24 \mathrm{~h}$ after training, whereas our rats remembered well at $24 \mathrm{~h}$ after training. Thus, we speculate that memories undergoing temporary suppression may be distinct from memories that fail to be recalled.

This is the first study to indicate a possible role for $\mathrm{PKM} \zeta$ in fear memory maintenance in young animals. The PKM $\zeta$ increase in the amygdala, but not hippocampus suggests that juveniles maintain contextual fear memories in a way that is similar to adults (Kwapis et al. 2009 but see Schuette et al. 2016). Amygdala involvement is also in agreement with human studies reporting a hyperactive amygdala in patients with post-traumatic stress disorder (PTSD; Koenigs and Grafman 2009).

The clinical relevance of our current findings lies in the malleability of memory in juveniles during reconsolidation, which provides a unique opportunity to treat traumatic memories associated with anxiety disorders (Centonze et al. 2005). Indeed, the intensity of reliving a traumatic event first experienced as a child is predictive of developing PTSD (Dalgleish et al. 2008) and over half of all mental disorders are diagnosed before adulthood (Kessler et al. 2005), while the neural circuitry underlying emotional memory is still developing (Casey et al. 2008). Therapeutic interventions can aim at modifying or disrupting memories during recall and thus permanently alter them (Hartley and Phelps 2010). When reconsolidation is prevented, memories do not 
return with the passage of time (Schiller et al. 2010). Moreover, targeting reconsolidation may be more promising than using extinction to attenuate fear memories, as extinguished memories can spontaneously recover or become reinstated in humans (Hartley and Phelps 2010) and juvenile mice (Pattwell et al. 2011). Finally, this study is a reminder that factors such as context and time can shift the outcome of extinction-based exposure therapy (Craske et al. 2008), especially early in development. Thus, a better understanding of the conditions under which fear memories are maintained throughout development is needed.

\section{Competing interest statement}

The authors declare that there is no conflict of interest.

\section{Acknowledgments}

This work is dedicated to the memory of Christoph P. Wiedenmayer, $\mathrm{PhD}$, whose untimely death deprived us of an excellent scientist, mentor, colleague, and friend. This research was supported by the National Institutes of Health grants 5R01MH071751, R21MH073994, and RCMI grant RR003037 from the National Center for Research Resources (NCRR).

\section{References}

Amaral OB, Luft T, Cammarota M, Izquierdo I, Roesler R. 2007. Temporary inactivation of the dorsal hippocampus induces a transient impairment in retrieval of aversive memory. Behav Brain Res 180: 113-118.

Baldi E, Mariottini C, Bucherelli C. 2008. Differential roles of the basolateral amygdala and nucleus basalis magnocellularis during post-reactivation contextual fear conditioning reconsolidation in rats. Neurobiol Learn Mem 90: 604-609.

Cain CK, Blouin AM, Barad M. 2003. Temporally massed CS presentations generate more fear extinction than spaced presentations. J Exp Psychol Anim Behav Process 29: 323-333.

Campbell BA, Jaynes J. 1966. Reinstatement. Psychol Rev 73: 478-480.

Campbell BA, Spear NE. 1972. Ontogeny of memory. Psychol Rev 79: $215-236$.

Casey BJ, Jones RM, Hare TA. 2008. The adolescent brain. Ann N Y Acad Sci 1124: $111-126$.

Centonze D, Siracusano A, Calabresi P, Bernardi G. 2005. Removing pathogenic memories: A neurobiology of psychotherapy. Mol Neurobiol 32: $123-132$

Chan T, Kyere K, Davis BR, Shemyakin A, Kabitzke PA, Shair HN, Barr GA, Wiedenmayer CP. 2011. The role of the medial prefrontal cortex in innate fear regulation in infants, juveniles, and adolescents. J Neurosci 31: $4991-4999$

Chan D, Baker KD, Richardson R. 2014. Relearning a context-shock association after forgetting is an NMDAr-independent process. Physiol Behav 148: 29-35.

Craske MG, Kircanski K, Zelikowsky M, Mystkowski J, Chowdhury N, Baker A. 2008. Optimizing inhibitory learning during exposure therapy. Behav Res Ther 46: 5-27.

Dalgleish T, Meiser-Stedman R, Kassam-Adams N, Ehlers A, Winston F, Smith P, Bryant B, Mayou RA, Yule W. 2008. Predictive validity of acute stress disorder in children and adolescents. Br J Psychiatry 192: 392-393.

Hartley CA, Phelps EA. 2010. Changing fear: The neurocircuitry of emotion regulation. Neuropsychopharmacol 35: 136-146.

Hayne H. 1990. The effect of multiple reminders on long-term retention in human infants. Dev Psychobiol 23: 453-477.

Heim C, Nemeroff CB. 2001. The role of childhood trauma in the neurobiology of mood and anxiety disorders: Preclinical and clinical studies. Biol Psychiatry 49: 1023-1039.

Hostinar CE, Sullivan RM, Gunnar MR. 2014. Psychobiological mechanisms underlying the social buffering of the hypothalamic-pituitary-adrenocortical axis: A review of animal models and human studies across development. Psychol Bull 140: 256-282.
Kabitzke PA, Barr GA, Chan T, Shair HN, Wiedenmayer CP. 2014. Medial prefrontal cortex processes threatening stimuli in juvenile rats. Neuropsychopharmacol 39: 1924-1932.

Kessler RC, Demler O, Frank RG, Olfson M, Pincus HA, Walters EE, Wang P, Wells KB, Zaslavsky AM. 2005. Prevalence and treatment of mental disorders, 1990 to 2003. N Engl J Med 352: 2515-2523.

Kim JH, Li S, Hamlin AS, McNally GP, Richardson R. 2012. Phosphorylation of mitogen-activated protein kinase in the medial prefrontal cortex and the amygdala following memory retrieval or forgetting in developing rats. Neurobiol Learn Mem 97: 59-68.

Koenigs M, Grafman J. 2009. Posttraumatic stress disorder: The role of medial prefrontal cortex and amygdala. Neuroscientist 15: 540-548.

Kwapis JL, Jarome TJ, Lonergan ME, Helmstetter FJ. 2009. Protein kinase Mzeta maintains fear memory in the amygdala but not in the hippocampus. Behav Neurosci 123: 844-850.

Kwapis JL, Jarome TJ, Gilmartin MR, Helmstetter FJ. 2012. Intra-amygdala infusion of the protein kinase Mzeta inhibitor ZIP disrupts foreground context fear memory. Neurobiol Learn Mem 98: 148-153.

Lee JL, Milton AL, Everitt BJ. 2006. Reconsolidation and extinction of conditioned fear: Inhibition and potentiation. J Neurosci 26: $10051-10056$

Li S, Richardson R. 2013. Traces of memory: Reacquisition of fear following forgetting is NMDAr-independent. Learn Mem 20: 174-182.

Li S, Callaghan BL, Richardson R. 2014. Infantile amnesia: Forgotten but not gone. Learn Mem 21: 135-139.

Mackenzie L, Nalivaiko E, Beig MI, Day TA, Walker FR. 2010. Ability of predator odour exposure to elicit conditioned versus sensitised post traumatic stress disorder-like behaviours, and forebrain $\Delta$ FosB expression, in rats. Neurosci 169: 733-742.

Miguez G, Witnauer JE, Laborda MA, Miller RR. 2014. Trial spacing during extinction: The role of context-US associations. J Exp Psychol Anim Learn Cogn 40: 81-91.

Pastalkova E, Serrano P, Pinkhasova D, Wallace E, Fenton AA, Sacktor TC. 2006. Storage of spatial information by the maintenance mechanism of LTP. Science 313: 1141-1144.

Pattwell SS, Bath KG, Casey BJ, Ninan I, Lee FS. 2011. Selective early-acquired fear memories undergo temporary suppression during adolescence. Proc Natl Acad Sci 108: 1182-1187.

Phillips RG, LeDoux JE. 1992. Differential contribution of amygdala and hippocampus to cued and contextual fear conditioning. Behav Neurosci 106: $274-285$

Rovee-Collier CK, Sullivan MW, Enright M, Lucas D, Fagen JW. 1980. Reactivation of infant memory. Science 208: 1159-1161.

Sacktor TC. 2008. PKMzeta, LTP maintenance, and the dynamic molecular biology of memory storage. Prog Brain Res 169: 27-40.

Schiller D, Monfils MH, Raio CM, Johnson DC, Ledoux JE, Phelps EA. 2010. Preventing the return of fear in humans using reconsolidation update mechanisms. Nature 463: 49-53.

Schuette SR, Fernández-Fernández D, Lamla T, Rosenbrock H, Hobson S 2016. Overexpression of protein kinase $\mathrm{M} \zeta$ in the hippocampus enhances long-term potentiation and long-term contextual but not cued fear memory in rats. J Neurosci 36: 4313-4324.

Sebastian V, Vergel T, Baig R, Schrott LM, Serrano P. 2013. PKM differentially utilized between sexes for remote long-term spatial memory. PLoS One 8: e81121.

Serrano P, Friedman EL, Kenney J, Taubenfeld SM, Zimmerman JM, Hanna J, Alberini C, Kelley AE, Maren S, Rudy JW, et al. 2008. PKM maintains spatial, instrumental, and classically conditioned long-term memories. PLOS Biol 6: 2698-2706.

Spear LP. 2000. The adolescent brain and age-related behavioral manifestations. Neurosci Biobehav Rev 24: 417-463.

Upton KJ, Sullivan RM. 2010. Defining age limits of the sensitive period for attachment learning in rat pups. Dev Psychobiol 52: 453-464.

Wiedenmayer CP, Barr GA. 2001. Developmental changes in c-fos expression to an age-specific social stressor in infant rats. Behav Brain Res 126: $147-157$

Wiedenmayer CP, Magarinos AM, McEwen BS, Barr GA. 2005. Age-specific threats induce CRF expression in the paraventricular nucleus of the hypothalamus and hippocampus of young rats. Horm Behav 47: 139-150.

Received April 5, 2016; accepted in revised form September 20, 2016. 


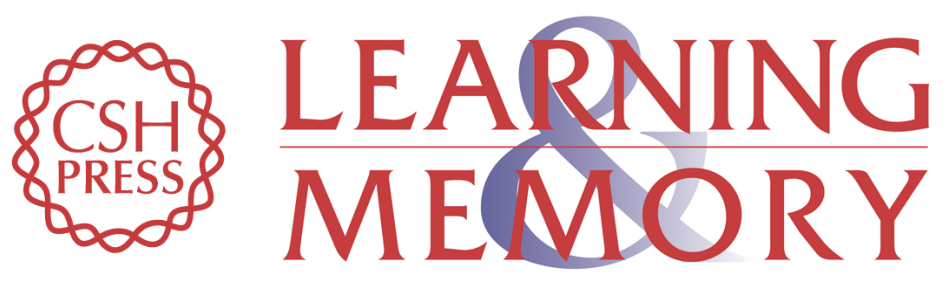

\section{Repeated recall and PKM $\zeta$ maintain fear memories in juvenile rats}

Chicora F. Oliver, Patricia Kabitzke, Peter Serrano, et al.

Learn. Mem. 2016, 23:

Access the most recent version at doi:10.1101//m.042549.116

References This article cites 39 articles, 9 of which can be accessed free at: http://learnmem.cshlp.org/content/23/12/710.full.html\#ref-list-1

Creative This article is distributed exclusively by Cold Spring Harbor Laboratory Press for the Commons first 12 months after the full-issue publication date (see

License http://learnmem.cshlp.org/site/misc/terms.xhtml). After 12 months, it is available under a Creative Commons License (Attribution-NonCommercial 4.0 International), as described at http://creativecommons.org/licenses/by-nc/4.0/.

Email Alerting Receive free email alerts when new articles cite this article - sign up in the box at the Service top right corner of the article or click here. 